\title{
CERVANTES Y LOS MAPAS: LA CARTOGRAFÍA COMO METÁFORA
}

\author{
ÁlVARO AlONSO \\ Universidad Complutense de Madrid \\ Para mi padre, topógrafo en ciernes \\ Para María
}

\begin{abstract}
A lo largo del siglo XVI, y como consecuencia del espectacular A desarrollo que estaba experimentando la cartografía europea desde 1450, los mapas se convirtieron en objetos de uso cotidiano. No sólo se valían de ellos, por razones prácticas, los navegantes, los viajeros o los estrategas, sino también innumerables lectores, a los que movía la simple curiosidad o el deseo de conocer. Prueba de ese éxito es la aparición del primer atlas, el Theatrum Orbis Terrarum, que Abraham Ortelius publicó en los Países Bajos en $1570 .{ }^{1}$ El propio Ortelius explica que, aunque son muchos los aficionados a la cartografía, apenas si pueden comprar mapas, ya que se trata de objetos caros, que ocupan, además, demasiado espacio: colgados de las paredes exigen casas muy grandes, que no todos pueden permitirse; y si se conservan enrollados, resultan incómodos de desplegar y consultar. El Theatrum -concluye triunfalmente su
\end{abstract}

1 Norman J. W. Thrower, Maps and Civilization. Cartography in Culture and Society, ChicagoLondres, The University of Chicago Press, 1996, págs. 58-90; G. R. Crone, Historia de los mapas, trad. Luis Alaminos y Jorge Hernández Campos, México, FCE, 2000, págs. 156-176. 
autor- viene a resolver todos esos problemas. ${ }^{2} \mathrm{Y}$, sin duda, la obra obedecía a una extensa demanda, como lo demuestran las 41 ediciones que conoció entre 1570 y $1621 .^{3}$

Como cualquier objeto de uso frecuente y que impresiona poderosamente la imaginación, los mapas adquirieron en seguida significados simbólicos, que la literatura no podía dejar de expresar. En las páginas que siguen me propongo estudiar esos valores tal y como aparecen en el Siglo de Oro, tomando como punto de partida la obra de Cervantes. Es bien conocida la influencia que ciertos textos geográficos ejercieron sobre la obra del novelista; y bastará recordar las deudas del Persiles con la Historia de Gentibus Septentrionalibus de Olao Magno. ${ }^{4}$ El propio escritor llama la atención sobre la improtancia de la cosmografía para la creación novelesca: de una manera irónica en el prólogo del Quijote y, más seriamente, en el discurso del canónigo en el capítulo 47 de la primera parte. Esa confluencia entre novela y geografía no es nueva. En sus reflexiones sobre la épica, Torquato Tasso había señalado que el poeta debe describir los escenarios de los hechos «a guisa di geografo». ${ }^{5}$

Pero lo que ahora me interesa no son las influencias de los tratados geográficos sobre la creación literaria, sino la forma en la que los textos cervantinos conciben y presentan los mapas: por coincidencia o por contraste, sus puntos de vista nos permitirán comprender mejor los de toda una época.

\section{Miniaturas}

Como ya he apuntado, los mapas ejercieron, desde muy pronto, una fascinación que no resulta inadecuado calificar de estética. Es posible que a ello contribuyeran los elementos ornamentales (dibujos, inscripciones, cartuchos), tan frecuentes en la obra de los primeros cartógrafos; pero parece indudable que entonces, como ahora, el principal atractivo de los mapas consistía en que ofrecían copias, y, más precisamente, copias en miniatura o modelos a escala de la realidad: el placer que proporcionaban era de la misma índole que el de las maquetas, los belenes o los veleros metidos en botellas. Los testimonios aparecen casi desde el primer momento. Unos versos laudatorios que preceden

2 Abraham Ortelius, Theatrum Orbis Terrarum, Antuerpia, 1570 (cito por el facsímil de Leyden, 1964).

${ }^{3}$ G. R. Crone, op. cit., págs. 165-166.

${ }^{4}$ L. Sletsjöe, «Cervantes, Torquemada y Olao Magno», Anales Cervantinos, 8 (1959-1960), págs. 139150.

5 El texto de Tasso corresponde al Giudizio sovra la «Conquistata», que cito a través de Franco Farinelli, «Luoghi, strade, spazio: tra poesia, cartografia e potere», en su libro I segni del mondo. Immagine cartografica e discorso geografico in età moderna, Florencia, La Nuova Italia, 1992, págs. 35 53: 38 . 
al atlas de Ortelius invitan al lector a recorrer sus páginas, y a medir así el ancho mundo en pequeños mapas («atque orbem brevibus vastum metire tabellis»). ${ }^{6} \mathrm{El}$ mismo juego entre lo grande y lo pequeño, entre la vastedad del espacio representado y la estrechez de los límites en los que se encierra, aparece en un célebre pasaje de las Soledades de Góngora. El peregrino, encaramado a un balcón natural, ve desplegarse ante él un extenso paisaje: ${ }^{7}$

Si mucho poco mapa les despliega, mucho es más lo que (nieblas desatando) confunde el sol y la distancia niega.

Para lo que ahora me interesa, el verso decisivo es el inicial, que Jammes glosa: «Poco mapa: aunque inmenso y variado, el panorama que están contemplando es poco mapa porque en un mapa geográfico ocuparía poco espacio». 8

La relación entre las representaciones cartográficas y las miniaturas aparece aún más explícita en un texto barroco tardío, El sabio instruido en la Naturaleza en cuarenta máximas políticas y morales de Francisco Garau. En un pasaje de claros ecos gracianescos, el autor explica que su estilo, denso y sentencioso, tiene el mismo mérito que los mapas, o que las representaciones del argumento de la Ilíada en una cáscara de nuez: ${ }^{9}$

Cúranse sus achaques con quintas essencias, no con los cocimientos. [...] Nadie admira escrita en un tomo la Ilíada de Homero, y todos celebran por maravilla verla reducida de manera que cogiera en la cáscara de una nuez. [...] Siempre fueron examen de los ingenios las cifras; y gala de la cosmografía un mapa donde se entiende un reino por solo un punto.

La misma imagen reaparece en el entusiástico soneto que el poeta italiano Federico Meninni dedica a un mapa de Europa. ¿Qué tiene de admirable -dice el terceto final- que todo Homero aparezca en una cáscara de nuez, si hemos conseguido apresar al continente entero en un trozo de papel?10

\footnotetext{
${ }^{6}$ Abraham Ortelius, ob. cit., folios de preliminares.

7 Luis de Góngora, Soledades, ed. Robert Jammes, Madrid, Castalia, 1994, pág. 239. Son los versos 194-196 de la Soledad I.

8 Luis de Góngora, ob. cit., pág. 238.

${ }^{9}$ El texto aparece recogido en el Corpus histórico de la RAE (Corde), por donde cito.

10 Federico Meninni, «Forza d'umano ingegno! In breve giro», en Poesia italiana del Seicento, ed. Luigi Felci, Milán, Garzanti, 1978, pág. 146; «Stupor non fia se de l'argiva musa,/ fu l'Iliade ristretta in una noce,/ quando l'Europa in picciol foglio è chiusa».
} 
Ese gusto por la miniatura, que parece universal,11 encuentra en los siglos XVI y XVII nuevas manifestaciones, que se equiparan, implícita o explícitamente, con la cartografía. Así, los primeros museos científicos se conciben como mundos abreviados, orbes in domo, según los llaman los textos de la época. El epitafio de uno de los más célebres coleccionistas del Renacimiento tardío, John Tradescant, explica que, al igual que una cáscara de nuez puede encerrar el desarrollo entero de la Ilíada, así los esfuerzos de Tradescant consiguieron encerrar en un espacio acotado «todo un universo de maravillas».12 También la ciudad cosmopolita, que atesora en su perímetro relativamente estrecho gentes y objetos de muy diversa procedencia, tiene algo de miniatura y, por tanto, de representación cartográfica. En Las firmezas de Isabela, Góngora llama a Sevilla "gran Babilonia de España,/ mapa de todas naciones,/ donde el flamenco a su Gante,/ y el inglés halla su Londres».13

En el ámbito propiamente literario, ya se ha visto cómo Francisco Garau compara la prosa conceptista con la tópica nuez y con los mapas; y una imagen parecida se aplica también al teatro. Al comienzo del acto II de El rufián dichoso, Cervantes hace que la misma Comedia, convertida en personaje, se explique de la siguiente manera: ${ }^{14}$

Ya la comedia es un mapa donde no un dedo distante verás a Londres y a Roma, a Valladolid y a Gante.

Muy poco importa al oyente que yo en un punto me pase desde Alemania a Guinea sin del teatro mudarme $[\ldots]$

Lo que está en juego en estas palabras es el problema de la unidad de lugar. ¿Debe la comedia, como manda Aristóteles, ocurrir en un escenario único? ¿O es posible, como hacen Lope y sus seguidores, saltar de un lugar a otro en la misma obra? La actitud de Cervantes con respecto a ese problema fue

11 Claude Lévi-Srauss, El pensamiento salvaje, trad. Francisco González Aramburo, México, FCE, 1972, págs. 43-54.

12 Citado en Paula Findlen, Possessing Nature. Museums, Collecting, and Scientific Culture in Early Modern Italy, Berkeley-Los Ángeles-Londres, University of California Press, 1996, pág. 17: «Whilst they (as Homer's Iliad in a nut)/ A World of Wonders in one closet shut».

13 Luis de Góngora, Teatro completo, ed. Laura Dolfi, Madrid, Cátedra, 1993, pág. 87. Son los versos 488-491 del acto I.

14 Miguel de Cervantes, Teatro completo, ed. Florencio Sevilla Arroyo y Antonio Rey Hazas, Barcelona, Planeta, 1987, pág. 326. 
siempre muy matizada, ${ }^{15}$ pero, estuviera o no de acuerdo con las novedades lopistas, percibe claramente cuál es su atractivo: el mismo que el de los mapas, el de abreviar la infinita extensión y variedad del mundo en un espacio cerrado.

La comparación no es exclusiva de Cervantes. En 1617, es decir, dos años después de la publicación de El rufián dichoso, aparece una loa anónima en la que, como es frecuente, se pide al público que concentre su atención en el escenario: 16

$$
\begin{aligned}
& \text { En este pequeño espacio, } \\
& \text { que es una mapa del mundo, } \\
& \text { hay Césares, hay soldados } \\
& \text { que no les agrada el triunfo. } \\
& \text { Hay Julios, hay Cipiones, } \\
& \text { hay Metelos y tribunos [...] }
\end{aligned}
$$

Mayor interés tiene un texto tardío, el de Juan Caramuel (1668), porque en él no sólo reaparece la metáfora del teatro-mapa, sino que lo hace -como en el pasaje de Cervantes- en el contexto del debate sobre las unidades. Sólo que, en este caso, lo que se discute es la unidad de tiempo. Como se sabe, los preceptistas aristotélicos aspiraban a que el tiempo real de la representación (unas 2 horas) coincidiera con el ficticio de la intriga. Pero, como esa exigencia parecía demasiado severa, admitieron que la intriga se desarrollara en un lapso de hasta 24 horas (unidad de tiempo). Más allá no se podía ir sin menoscabo de la verosimilitud: no era creíble -se argumentaba- que se representaran años y años en el breve espacio de un par de horas. Sin embargo, Lope había roto con ese precepto; y sus seguidores se lanzaron a buscar justificaciones teóricas para su innovación. Caramuel esgrime una basada en la analogía: si los cartógrafos comprimen el espacio, y eso no afecta a la «verosimilitud» de los mapas, ¿por qué los dramaturgos no podrán hacer lo mismo con el tiempo, resumiendo toda la vida del personaje?:17

Sane, comoedia est picturae simillima; ergo, si in parva tabula potest tota terra, aut etiam totum caelum depingi, cur non potest in brevi comoedia [...] tota vita Nestoris repraesentari?

\footnotetext{
${ }^{15}$ Edward C. Riley, Teoría de la novela en Cervantes, $3^{\text {a }}$ ed., Madrid, Taurus, 1981, págs. 35-46; Alban K. Forcione, Aristotle and the «Persiles», Pinceton, Princeton University Press, 1970, págs. 91-130.

16 Aparece recogida en Corde, pero cito por Emilio Cotarelo y Mori, Colección de entremeses, loas, bailes, jácaras y mojigangas desde fines del siglo XVI a mediados del XVII, tomo I, vol. II, (NBAE, 18), Madrid, Bailly-Baillière, 1911, pág. 453 a-b.

17 Federico Sánchez Escribano y Alberto Porqueras Mayo, Preceptiva dramática española del Renacimiento y el Barroco, 2ª ed., Madrid, Gredos, 1972, pág. 196.
} 
Aunque el texto comienza hablando de pintura, unas tabulae que incluyen toda la tierra e incluso todo el cielo sólo pueden ser un mapamundi y una carta astral.

El argumento de Caramuel no es nuevo. Lo utilizan, aunque con imágenes diferentes, el teórico Francisco de Barreda y Tirso de Molina. En 1622, Barreda señala que no hay nada censurable en romper la unidad de tiempo, presentando en dos horas largas historias. ¿No representó Arquímedes «en poco vidro toda la máquina del cielo»? El objeto al que se refiere el tratadista ha de ser algo parecido a una esfera armilar, es decir, de acuerdo con la definición académica, un instrumento astronómico compuesto de aros que representan los círculos más importantes de la esfera celeste, y en cuyo centro suele colocarse un globo terráqueo. Aunque se trata de una metáfora diferente, salta a la vista su relación con el mapa. Dos años después, en 1624, Tirso defiende también la ruptura de la unidad de tiempo: el dramaturgo puede condensar el tiempo igual que la perspectiva pictórica abrevia el espacio: 18

que no en vano se llamó la poesía «pintura viva», pues, imitando la muerta, ésta, en el breve espacio de vara y media de lienzo, pinta lejos y distancias que persuaden a la vista a lo que significan, que no es justo que se niegue la licencia que conceden al pincel a la pluma $[. .$.

Puede concluirse, por tanto, que a partir de 1610-20 surge una serie de metáforas muy parecidas, que cumplen la misma función de describir (y, casi siempre, defender) el nuevo tratamiento del tiempo y el espacio en la dramaturgia lopista: la imagen del mapa en Cervantes y Caramuel; la de la esfera armilar en Barreda; la de la pintura perspectivista en Tirso.

Vale la pena detenerse todavía un momento en esa relación pinturacartografía que plantean los textos de Tirso y Caramuel. Con frecuencia, ambas imágenes se alternan, e incluso se confunden. Sin salir del ámbito teatral, una loa de comienzos del siglo XVII se pregunta cómo es posible representar grandes espacios en un pequeño escenario. La respuesta, una vez más, es analógica: ${ }^{19}$

Suele el diestro pintor, cuando la tabla, blanco de su pintura y de su intento, breve lugar le ofrece, espacio corto, y ha de pintar en ella un mar soberbio, una grande ciudad, un mar altivo, [...]

${ }^{18}$ Federico Sánchez Escribano y Alberto Porqueras Mayo, ob. cit., pág. 210 para Tirso y 219 para Barreda.

${ }^{19}$ Aparece en Corde, pero cito por Emilio Cotarelo y Mori, ob. cit., pág. 235 b. 
valerse de los lejos, reduciendo a proporción pequeña grandes cosas.

Se habla de cuadros, pero la mención a las ciudades pintadas desde lejos hace pensar inmediatamente las vistas urbanas que muchos atlas incluyen entre sus páginas desde finales del siglo XVI.

Fuera del teatro, la misma alternancia cuadros-mapas se presenta en el texto de las Soledades que he citado al comienzo de este epígrafe. Relatando, en 1565, su ascensión al Monte Baldo, el naturalista italiano Francesco Calzolari señala que desde la cima veía a sus pies campos, ciudades y castillos, "como en un hermoso cuadro flamenco».20 Cabe sospechar que la imagen era frecuente para describir un paisaje visto desde arriba, así que cuando Góngora pesenta como poco mapa la naturaleza que ve el peregino, no hace sino reemplazar -como Caramuel con respecto a Tirso- una imagen más convencional (la del cuadro) por otra más llamativa (la del mapa).

De hecho, cuando se representaba un espacio abarcable con la mirada, podía no ser clara la diferencia entre cuadros y mapas. Por un lado, no se había desarrollado todavía un sistema de signos abstractos para las representaciones cartográficas; por otro, aunque muchos levantamientos topográficos se realizaban ya con procedimientos trigonométricos, otros muchos seguían haciéndose a ojo, desde lo alto de una torre o una colina: el pintor-cartógrafo, como lo llama Crone, siguió siendo una figura habitual a lo largo de los siglos XVI y XVII. ${ }^{21} \mathrm{El}$ propio Góngora parece vacilar entre ambas representaciones mentales, pues si bien es cierto que habla de mapa, alude luego a una especie de sfumato, más característico de la pintura que de los mapas en sentido estricto: «muchos es más lo que (nieblas desatando)/ confunde el sol y la distancia niega».

No obstante, y a pesar de esas vacilaciones, la cartografía se concebía como algo distinto de la pintura «artística», y competía con ella como ejemplo y paradigma de toda imitación reductora. En algunos contextos había que pensar necesariamente en los mapas: el mismo Cervantes no hubiera podido decir con sentido que la comedia, como un cuadro, coloca juntos a Valladolid y a Londres, porque los cuadros no suelen representar espacios tan amplios. Como mecanismos de reducción del mundo, como artificios para encerrar «mucho en poco», los mapas eran de una eficacia muy superior a la pintura.

${ }^{20}$ No he podido ver el texto de Calzolari, Il viaggio di Monte Baldo, que cito a través de Paula Findler, ob. cit., pág. 182.

${ }^{21}$ G. R. Crone, op. cit., págs. 124-129. 


\section{Apropiarse del mundo}

Uno de los motivos del placer que producen los modelos a escala es que, al reducir el tamaño de los objetos, los vuelven más manejables o, al menos, producen esa ilusión. En un pasaje de El licenciado Vidriera, el protagonista y sus compañeros de armas han llegado a Italia, y se dirigen, naturalmente, a una hostería:22

\footnotetext{
Y habiendo hecho el huésped la reseña de tantos y tan diferentes vinos, se ofreció de hacer parecer allí sin usar de tropelía, ni como pintados en mapa, sino real y verdaderamente, a Madrigal, Coca, Alaejos, y a la Imperial más que Real Ciudad, recámara del dios de la risa; ofreció a Esquivias, a Alanís, a Cazalla, Guadalcanal y la Membrilla [...]
}

Todo el fragmento se construye sobre un doble sentido. El ventero se compromete a presentar los pueblos que menciona; pero, en lugar de cumplir esa imposible promesa, se da por satisfecho con sacar los vinos que proceden de tales lugares y que, con frecuencia, llevan sus nombres. No obstante, quizá el juego es más serio de lo que parece, porque la gastronomía es una forma muy eficaz de enraizarse en un lugar o de evocarlo en la memoria. Los ejemplos, literarios o no, podrían multiplicarse. «Sol de Andalucía embotellado», dice un viejo anuncio de manzanilla, que convierte al sol, y a Andalucía misma, en refinadas miniaturas. Y describiendo un viaje a Curragh, Fernando Savater termina así la descripción de una comida:23

Pero estos sucintos alimentos son sólo el pretexto para acompañar la primera pinta de Guinness, el Santo Grial, la comunión necesaria de cada día con el nublado y mágico corazón de Irlanda.

El énfasis irónico de la frase -tan cervantino, por otra parte- no oculta la seriedad de la idea, que se revela, ya sin ironía, en el lírico final.

De manera que, al emparejar vinos y mapas, el fragmento no hace sino comparar, señalando sus diferencias, pero también su unidad esencial, dos formas simbólicas de apropiarse de un lugar: una, visual y abstracta; otra, más concreta, basada en los sentidos del olfato y el gusto. Pero al mismo tiempo que señala la capacidad de evocación de los mapas, el texto muestra también sus límites, al recordar que no debe confundirse la cosa misma con su

22 Miguel de Cervantes, El licenciado Vidriera, en Novelas ejemplares, II, ed. Juan Bautista Avalle-Arce, Madrid, Castalia, 1982, pág. 110.

${ }^{23}$ Fernando Savater, A caballo entre milenios, Madrid, Aguilar, 2001, pág. 113. 
representación: «no pintados en mapa..., sino real y verdaderamente». Esa misma advertencia aparece aún más clara en un pasaje del Quijote.

\section{Viajar en el mapa}

Desde que los mapas se convirtieron en objetos familiares a la experiencia de todo europeo culto, cobró cuerpo la posibilidad de viajar sin salir de casa. Los versos con los que se abre la obra de Ortelius dan testimonio de esa nueva aspiración: hojeando las páginas del atlas -dicen- el lector podrá recorrer todas las regiones del mundo, visitar lejanas ciudades y conocer pueblos extraños. ${ }^{24}$ En 1570 la afirmación era ya un tópico. Bastante antes de que lo recogieran los versos a los que me acabo de referir, lo habían utilizado (ya en el primer tercio del siglo XVI) dos autores a los que Cervantes conocía muy bien.

En su Colloquium senile, Erasmo pone en escena a varios ancianos, uno de los cuales, Glición, encarna el ideal de vida serena, apacible y honradamente cristiana que tantas veces aparece en la pluma del autor. Uno de los amigos del personaje le pregunta si no le causa hastío vivir siempre en el mismo lugar; a lo que Glición responde que los viajes, si bien tienen algún deleite, entrañan numerosos peligros, de manera que es «preferible y más seguro rodear todo el mundo en una tabla de geografía». ${ }^{25}$

La idea debía de resultar especialmente atractiva para Erasmo, pues la repite en su Diálogo de un soldado y un cartujo. Este último vive feliz en su celda, ayudado por unos cuantos libros y por «este napamundi que aquí tengo", gracias al cual puede recorrer toda la tierra más cómoda y seguramente que si lo hiciera de verdad. ${ }^{26}$

Sin la carga religiosa del humanista de Rotterdam, la idea aparece también en la Sátira III, que Ariosto dirigió a su primo Annibale Malaguccio. El género mismo de la sátira epistolar ( $\mathrm{y}$, desde luego, el temperamento del poeta) orientan esos versos hacia el modelo de Horacio. Como el autor latino, el italiano sueña una vida lejos del tráfago de la corte, sin preocupaciones ni sobresaltos. Ariosto aclara a su destinatario que no quiere viajar por Inglaterra,

\footnotetext{
24 Abraham Ortelius, op. cit., versos preliminares.

${ }^{25}$ El texto, correspondiente a la traducción renacentista de Alonso de Virués, aparece en Corde, pero cito por Marcelino Menéndez Pelayo, Orígenes de la novela, IV (NBAE, 21), Madrid, Bailly Baillière, 1915, pág. 159b.

${ }_{26}$ Marcelino Menéndez Pelayo, op. cit., pág. 174 a-b. Mantengo la forma napamundi, enmendada por Menéndez Pelayo, ya que parece más próxima a la etimología italiana de la palabra (nappa).
} 
Hungría, Francia ni España. Ya conoce el norte de Italia, y no quiere moverse más:27

Esto me basta; el resto de la tierra
sin pagar hospedaje, lo iré viendo
(esté en guerra o en paz) con Tolomeo,
y el mar entero surcaré en los mapas,
sin hacer votos cuando el cielo anuncie
tormenta, y más seguro que en un leño.

A la vista de esos textos, adquiere un relieve especial la afirmación de don Quijote en el capítulo sexto de la segunda parte:28

de todos ha de haber en el mundo, y aunque todos seamos caballeros, va mucha diferencia de los unos a los otros; porque los cortesanos [...] se pasean por todo el mundo mirando un mapa, sin costarles blanca, ni padecer calor ni frío, hambre ni sed; pero nosotros, los caballeros andantes verdaderos, al sol, al frío, al aire [...] medimos toda la tierra con nuestros mismos pies [...]

El viaje en el mapa, que los textos anteriores valoraban tan favorablemente, aparece aquí relacionado con el cerrado egoísmo de los cortesanos. Pero, más allá de ese blanco concreto, ¿no se dirige la crítica contra todos aquellos que se conforman con moverse en el mapa (es decir, en la imaginación)? Dejemos al cartujo, porque Cervantes fue siempre muy cauto a la hora de enjuiciar los móviles religiosos, y recordemos sólo al apacible burgués del coloquio de los viejos. Es claro que el novelista no sentiría demasiada simpatía hacia él, como no la sintió hacia el Caballero del Verde Gabán, ${ }^{29}$ tan próximo a Glición en sus ideas y su modo de vida. Y por lo que respecta al filósofo horaciano de la sátira de Ariosto, Cervantes podría compartir su rechazo de la corte, no su ceguera ante el esplendor de la aventura y el riesgo. ${ }^{30}$ Tanto Ariosto como Erasmo y Ortelius destacan, sin excepción, la seguridad del viaje imaginado. Pero en el universo de Cervantes, la seguridad no es un valor, sino más bien todo lo

\footnotetext{
27 Ludovico Ariosto, Sátiras, ed. bilingüe de José María Micó, Barcelona, Península, 1999, pág. 57. Son los versos 61-66.

${ }_{28}$ Miguel de Cervantes, Don Quijote de la Mancha, edición dirigida por Francisco Rico, Barcelona, Crítica, 1998, pág. 672.

29 Sobre el del Verde Gabán y su enfrentamiento ideológico con don Quijote, Francisco Márquez Villanueva, Personajes y temas del «Quijote», Madrid, Taurus, 1975, págs. 147-227.

30 Desde una perspectiva muy distinta a la de los mapas, el antihoracianismo del pasaje ha sido señalado por Félix Carrasco, «Cervantes y Góngora: labradores, cabreros y caballeros», en Actas del II Congreso Internacional de la Asociación de Cervantistas, ed. Giuseppe Grilli, Nápoles, Gallo, 1995, págs. 405-418: 416.
} 
contrario, y cualquier moral que la busque con demasiado ahínco resulta inmediatamente sospechosa.

Sin embargo, lo que está en juego no son sólo razones morales. Don Quijote no quiere conformarse con los mapas, de la misma manera que no quiere limitarse a la simple lectura de los libros de caballerías: necesita llevarlos a la práctica, aunque sea de la forma distorsionada que todos conocemos. Su imaginación no sabe funcionar en un mundo puramente ficticio, y necesita el apoyo de unos hechos, unos objetos y unos viajes reales para poder levantar el vuelo. Como las novelas, los atlas son copias del mundo que dejan fuera los riesgos de la realidad, pero también su insustituible espesor.

Así que al rechazar el tópico del feliz viaje en el mapa, el pasaje de Cervantes tenía implicaciones de mayor envergadura. Es posible que el novelista pensara en los textos de Ariosto y de los Colloquia, pero no se necesita suponer una relación deliberada: voluntaria o involuntariamente, las palabras de don Quijote invalidan los ideales de vida de Horacio y de los erasmistas.

\section{Estar o no estar en los mapas}

En una época en la que zonas muy extensas del mundo estaban todavía por descubrir, los viajeros se encontraban muchas veces con montes, ríos o islas de los que no se tenía noticia y que, por consiguiente, ningún cartógrafo había recogido: la expresión «que no está en los mapas» se refiere, con frecuencia, a estas tierras incógnitas que el explorador contempla por primera vez y que, gracias a él, se incorporan al universo conocido.

Pero, desde muy pronto, la expresión adquiere un significado diferente. A raíz de los descubrimientos empezó a hacerse evidente que las descripciones geográficas, y los mapas, no podían hacerse partiendo de argumentos deductivos ni de informaciones indirectas: había que ir y mirar directamente. ${ }^{31}$ Pero si los mapas son -o deberían ser- el registro de lo que se ha visto con los ojos y se ha tocado con las manos, «lo que no está en el mapa» es lo que corresponde a las lucubraciones teóricas o al mero trabajo de la imaginación. Cervantes utiliza una expresión parecida al final de Pedro de Urdemalas. Allí el protagonista critica las inverosimilitudes de las comedias de moda, en las que el protagonista resuelve victoriosamente todos sus problemas «y al fin viene a ser rey de un cierto reino/ que no hay cosmografía que lo muestre».32 La frase aparece también, con un sutil juego irónico, en uno de los discursos de don

\footnotetext{
${ }^{31}$ Las relaciones entre el pensamiento geográfico y la génesis del empirismo europeo, se analizan en el apasionante libro de Margarita Bowen, Empiricism and Geographical Thought. From Francis Bacon to Alexander von Humboldt, Cambridge, Cambridge University Press, 1981.

32 Miguel de Cervantes, Teatro completo..., p. 719.
} 
Quijote. Conversando con Sancho, el hidalgo explica que en las novelas de caballerías el protagonista parece de oscuro origen, pero al final resulta ser «hijo de un valeroso rey de no sé qué reino, porque creo que no debe de estar en el mapa».33 Como don Quijote no puede dudar de la existencia de ese reino, lo que quiere decir con sus palabras es que los mapas no lo registran por tratarse de un territorio lejano y desconocido. Pero el lector entiende la frase en su segunda acepción, la que niega realidad objetiva al reino en cuestión. De manera que, sin saberlo, don Quijote está diciendo la verdad, y reconociendo el carácter alucinatorio de su mundo.

La expresión tiene aún un tercer significado, que aparece en las palabras del sacristán en Los baños de Argel. El cadí le pregunta por su tierra, y el sacristán contesta: ${ }^{34}$

\author{
No está en el mapa. \\ Es mi tierra Mollorido, \\ un lugar muy escondido \\ allá en Castilla la Vieja.
}

«No estar en el mapa» equivale, por tanto, a carecer de importancia. Se advertirá que esa tercera acepción matiza, y hasta contradice, la segunda. El mapa ya no es el registro perfecto de la realidad (pero ¿qué copia lo es del todo?), sino una representación selectiva, basada en criterios convencionales. ${ }^{35} \mathrm{~A}$ estas alturas del siglo XVII ocurre ya con el mapa lo que más tarde ocurrirá con la fotografía: que, por una parte, aparece como el arquetipo de toda representación objetiva (cuando se habla, por ejemplo, de «realismo fotográfico»); pero, por otra, se tiene conciencia más o menos oscura de su naturaleza convencional, estrechamente relacionada con el concepto de poder: así que «no salir en la foto» -como «no estar en los mapas»- viene a ser sinónimo de haber quedado al margen de los grupos que toman las decisiones. Quevedo advirtió bellamente ese característica de los mapas en su versión cartográfica del tópico de la vida retirada: ${ }^{36}$

\footnotetext{
33 Miguel de Cervantes, Don Quijote..., p. 232.

34 Miguel de Cervantes, Teatro completo..., p. 213. Son los versos726-729 de la Jornada I.

35 Las distorsiones que los mapas imponen a la realidad cuando la representan son el eje de los clásicos trabajos de Harley. Puede leerse una selección en Jhon Brian Harley, The New Nature of Maps. Essays in the History of Cartography, introducción J. H. Andrews, ed. Paul Laxton, BaltimoreLondres, The John Hopkins University Press, 2001.

36 Aparece recogido en Corde, pero cito por Francisco de Quevedo, Epistolario completo, ed. Luis Astrana Marín, Madrid, Reus, 1946, pág. 106.
} 
Yo me retiré a esta Torre [la Torre de Juan Abad] para vacar a este negocio del ocio, y por gozar a mi gusto desta feliz ociosidad. [...] Este pequeño lugar del mundo es ignorado de la antigua y la nueva geografía, y Mercator no habla dél más que Tolomeo.

Puesto que el sabio estoico desdeña la riqueza y el poder, sus lugares naturales son «los que no están en los mapas», ya que éstos suelen regirse por los criterios contrarios de la pujanza política, comercial o demográfica. Vale la pena observar, de paso, la referencia a Mercator. Cervantes no parece haber conocido al gran cartógrafo, o, al menos, no advirtió su importancia. Para él, la cartografía y la cosmografía seguían resumiéndose en el nombre de Tolomeo. La mayor juventud, pero, sobre todo, la abrumadora cultura de Quevedo le habían familiarizado con la obra de Mercator: pudo completar así la referencia ya un poco rancia al sabio griego con otra de indudable actualidad: el Atlas de Mercator, el primero en llevar ese título, es de $1595 .{ }^{37}$

\section{Mapas y calvas. Final}

La mención a Quevedo evoca uno de los tratamientos más frecuentes de los mapas en la literatura de los Siglos de Oro. Puesto que aparece cubierta de líneas incomprensibles para el ojo no entrenado (paralelos, meridianos, etc.), la superficie del mapa se relaciona con cualquier dibujo abigarrado y sin aparente sentido. El ejemplo más famoso son las calvas mapamundi de Quevedo:38

Hay calvas de mapamundi, que con mil líneas se cruzan, con zonas y paralelos de carreras que las surcan.

Ese aspecto, sin embargo, no llamó la atención de Cervantes. Como he intentado mostrar, en su obra los mapas aparecen como:

1) una metáfora del teatro $y$, en general, de cualquier copia reductora del mundo, con todos los atractivos y las limitaciones que tales copias presentan;

\footnotetext{
37 G. R. Crone, op. cit., pág. 164.

38 Francisco de Quevedo, «Madres, las que tenéis hijas», en Obras completas, I. Poesía original, $2^{\mathrm{a}}$ ed., ed. José Manuel Blecua, Barcelona, Planeta 1968, p. 837.
} 
2) un simulacro, que pretende reemplazar, insatisfactoriamente, al viaje y la aventura reales;

3) una representación objetiva del mundo, que excluye el ámbito de la fantasía y la ficción; pero también

4) una representación selectiva y, por consiguiente, distorsionada de esa misma realidad.

Lo que interesó a Cervantes no fue el aspecto visual de los mapas, sino su esencia, el problema mismo que la cartografía presenta de una forma paradigmática, y que vertebra también muchas páginas del Quijote, si no la novela entera: el problema de la relación entre el mundo real y nuestras formas de representarlo. 